\title{
Macronutrient Preload effect on Glycaemic Control and Pregnancy Outcome in Gestational Diabetes Mellitus
}

\author{
Cai Jingjing ${ }^{1}$, Lv Jing ${ }^{1}$, Guo Qianying ${ }^{1}$, Wang Boshi ${ }^{1}$, Gunnar Norstedt ${ }^{2}$, Magnus Sederholm², Liu Peng ${ }^{1{ }^{*}}$ \\ ${ }^{1}$ Department of Clinical Nutrition, Peking University People’s Hospital, Beijing, China \\ ${ }^{2}$ Department of Women's and Children's Health, Karolinska Institute, Stockholm, Sweden \\ *Corresponding author: liupengpku@163.com
}

Received August 07, 2018; Revised September 12, 2018; Accepted September 26, 2018

\begin{abstract}
Objective: To investigate the effect of macronutrient preload treatment, MPT, on glycemic control and pregnancy outcome in gestational diabetes mellitus, GDM. Study Design: 40 patients with GDM were randomized to either MPT in addition to health education and dietary guidance $(\mathrm{n}=25)$ or health education and dietary guidance only $(\mathrm{n}=15)$. MPT was given three times/day, 30 minutes before regular meals and continued until term. Participants were subjected physical examination, laboratory analysis and pregnancy outcomes. Results: The time until the participant reached stable euglycemia was shorter in the preload group compared to controls $(P<0.05)$, in patients $\geq 30$ years old $(1.3 \pm 0.55$ versus $2.5 \pm 1.1$ weeks, $\mathrm{P}<0.05)$, in pre-gestational $\mathrm{BMI}<24 \mathrm{~kg} / \mathrm{m}^{2}(1.3 \pm 0.58$ versus $1.9 \pm 0.69$ weeks, $\mathrm{P}<0.05)$ and in pre-gestational $\mathrm{BMI} \geq 24 \mathrm{~kg} / \mathrm{m}^{2}(1.2 \pm 0.44$ versus $2.6 \pm 1.32$ weeks, $\mathrm{P}<0.05)$. The birth weight in the subgroup of BMI $>24 \mathrm{~kg} / \mathrm{m}^{2}$ was lower in the MTP group compared to the control group (3124 $\pm 523 \mathrm{~g}$ versus $3780.0 \pm 472 \mathrm{~g}, \mathrm{P}<0.05$ ). Increase of $\mathrm{HbA1c} \geq 5 \%$ was significantly lower after preload treatment. Conclusion; MPT can safely be used in patients with gestational diabetes mellitus for effective control of blood glucose. The significant reduction of birth weight in participants with pre-gestational BMI $\geq 24 \mathrm{~kg} / \mathrm{m}^{2}$ indicates that preload can be used to control negative effects of hyperglycemia, with reduced risk for complications during delivery.
\end{abstract}

Keywords: gestational diabetes mellitus, macronutrient preload treatment, glycemic control, pre-gestational BMI, nutritional therapy

Cite This Article: Cai Jingjing, Lv Jing, Guo Qianying, Wang Boshi, Gunnar Norstedt, Magnus Sederholm, and Liu Peng, "Macronutrient Preload effect on Glycaemic Control and Pregnancy Outcome in Gestational Diabetes Mellitus." Journal of Food and Nutrition Research, vol. 6, no. 9 (2018): 584-589. doi: 10.12691/jfnr-6-9-7.

\section{Introduction}

Gestational diabetes mellitus, GDM, is defined as any degree of glucose intolerance with onset or first discovery during pregnancy [1]. Untreated GDM predisposes the pregnant woman and her offspring to a variety of risks both during pregnancy and delivery as well as later in life [2]. There is a higher risk of hypertension and preeclampsia for the mother, a higher prevalence of fetal distress and complications during delivery and a greater propensity to develop metabolic syndrome/type 2 diabetes [3]. The association between GDM and potential deleterious effects on neurodevelopment in the offspring must also be considered, GDM may have a negative impact on cognition, including in the long term [4].

In recent years, GDM screening has become more established and diagnostic criteria have become better standardized. Still the prevalence of GDM differs greatly between countries, in part dependent on which criteria are being used [5]. There are no uniform criteria for GDM in China, most hospitals use 75 gram oral glucose tolerance test (OGTT) in women with a risk for GDM, which in a recent study show a prevalence of GDM and abnormal glucose values of $8.9 \%$ [6]. In 2010 the International Association of Diabetes and Pregnancy Study Group (IADPSG) launched new diagnostic criteria which had lower cutoff values than most of the earlier used criteria, and therefore increased the prevalence of GDM [7]. Applying the IADPSG criteria showed a GDM prevalence of $14.7 \%$ in Beijing, where the GDM women also had a higher incidence of LGA (large for gestational age), macrosomia and more complex deliveries [6].

Diet guidance is a cornerstone in controlling the blood glucose level in GDM, so as to reduce the incidence of pregnancy complications and perinatal complications. Most reviews of dietary approaches does however not show significant efficacy [8]. A recent development of medical nutrition therapy is macronutrient preload treatment where a small and specific amount of nutrients is provided before regular meals. The rationale behind macronutrient preload treatment is that this starts the release of incretin hormones such as GLP-1 and insulin before meals [9], which attenuates the glycemic response to the subsequent meal. The earlier release of incretin hormones also delays gastric emptying and gut motility, and increases satiety earlier through a direct action on the hypothalamus [10]. 
Data are accumulating that macronutrient preload treatments have positive effects on metabolism and type 2 diabetes mellitus [11,12]. In the present study we compared the effect of macronutrient preload treatment with conventional nutritional intervention in patients with gestational diabetes. Most of the dietary recommendations are based on glucose control data as primary endpoints in fact "surrogate endpoints". More important would be to study the effect of dietary recommendations on clinical endpoints such as newborn weight, need of assistant deliveries etc. We therefore also included newborn outcomes in our study.

\section{Materials and Methods}

\subsection{Subjects}

From June 2015 to March 2016, 40 patients (24-28 gestational weeks, singletons) with gestational diabetes mellitus and average age of $32 \pm 3.3$ years (25-39) were enrolled from the pregnancy nutrition outpatient department of Peking University People's Hospital. The diagnostic criteria for gestational diabetes were according to the IADPPSG standard [6] as accepted by ADA. (75g, 2-h oral glucose tolerance test, one or more of the following; fasting plasma glucose $\geq 5.1 \mathrm{mmol} / \mathrm{l}$, 1-hour plasma glucose $\geq 10.0 \mathrm{mmol} / \mathrm{l}$, 2-hour plasma glucose $8.5 \mathrm{mmol} / \mathrm{l}) 25$ patients were randomized to the intervention group (preload treatment in addition to health education and dietary guidance), and 15 patients were randomized to the control group (intervention with health education and dietary guidance only). The intervention lasted until delivery. This study was carried out in accordance with the recommendations of China Medical Nutrition Therapy Guideline for Diabetes (2013), Chinese Diabetes Society, and Dietitian Professional Committee, Chinese Medical Doctor Association, with written informed consent from all subjects in accordance with the Declaration of Helsinki. The protocol was approved by the Ethical Committee of Peking University People's Hospital.

\subsection{Methodology}

The patients recorded their diet and monitored blood glucose on their own and came to hospital for regular assessments of weight, liver function, renal function, total protein, albumin (TP, Alb), hemoglobin (Hb), and glycosylated hemoglobin (HbA1c) examinations by blood sampling, as well as pregnancy outcome observation, including delivery mode, postpartum hemorrhage and fetal macrosomia. The patients underwent height measurement without shoes, and weight measurement under fasting and shoe-free conditions, with a RGZ-120 weight and height scale (Jiangsu Wujin Weighing Apparatus Co., Ltd., China) used for height and bodyweight measurement.

The time to normalize elevated blood glucose (glucose control stabilization time) during gestational week 24 - 28 was carried out as follows. Patients were instructed to measure their fasting blood sugar every morning and their 2-hour postprandial blood sugar after breakfast, lunch and dinner using a glucose meter (ACCU-CHEK). The time needed to stabilize blood sugar was defined as the time (weeks) when more than $90 \%$ blood glucose measurements were within the normal range according to IADPSG [6].

Two dietitians have participated in this research. They were trained before the study to provide standardized health education and dietary guidance to all participants. Uniform diet record forms were used to document the diet of two week days and one weekend day. Uniformly designed cups with an $\mathrm{ml}$ scale were used to prepare preload solution (NGC Preload, see below). We used a schedule for every patient to meet the dietitians. The patients made the regular contact in the first and second weeks, then at least one time a month until delivery. They brought their diet records (3 days a week) every time they come to the dietitians.

\subsection{Macronutrient Preload Treatment}

For the intervention group, a macronutrient preload nutrition powder (NGC Preload; imported from Sweden, (Indevex Biotech, original packing, provided by Tianjin Health Promotion Technology Co. Ltd.) was given as three premeals 30 minutes before ordinary meals (meal times were: 7:30, 11:30, and 17:30). The NGC Preload product consists $100 \%$ of natural food ingredients (pea-protein, whey protein, egg albumin, $\Omega 3 / 6$ fatty acids, whole eggs, apple and sugar beet fiber). Each serving of NGC Preload (18 gram) contains $7.6 \mathrm{~g}$ protein, $1.8 \mathrm{~g}$ fat (saturated and unsaturated fat are $0.6 \mathrm{~g}$ and $1.2 \mathrm{~g}$ respectively), $1.6 \mathrm{~g}$ fiber and $5.2 \mathrm{~g}$ carbohydrates, which provided 71 kcal energy and a low Glycemic Index, GI (28\% of reference value $100,<55 \%$ is considerad as low GI). Each sachet was dissolved in water before use. The patient directly drank the entire preparation made by mixing the powder with $150 \mathrm{ml}$ water. After drinking the preparation, the patient drank another100 ml water and then started a regular meal half an hour later.

Statistical processing SPSS19.0 was used to conduct statistical analysis. The measurement data were expressed as mean \pm standard deviation. Unpaired $\mathrm{T}$ test was used for testing the difference between two groups, where $\mathrm{P}<0.05$ indicates statistical significance. Categorical data was expressed as number and percentage, and $\chi^{2}$ test was used for testing the difference between two groups, where $\mathrm{P}<0.05$ indicates statistical significance.

\section{Results}

\subsection{Description of the Patients}

The patients' age, pre-gestational BMI, enrolment body weight, pre-delivery body weight, gestational body weight increase and average weekly body weight increase showed no statistical difference $(\mathrm{P}>0.05)$, as shown in Table 1 . The physical examination indexes showed no statistical differences between the two groups after grouping by age (cut off value $\geq 30$ years) and BMI (cut off value $\geq$ $24 \mathrm{~kg} / \mathrm{m}^{2}(\mathrm{P}>0.05)$. 
Table 1. Result of General Physical Examination

\begin{tabular}{lcc}
\hline & $\begin{array}{c}\text { Control group } \\
(\mathrm{n}=15)\end{array}$ & $\begin{array}{c}\text { Intervention group } \\
(\mathrm{n}=25)\end{array}$ \\
\hline Age (year) & $32 \pm 3.1$ & $33 \pm 3.5$ \\
Pre-gestational BMI $\left(\mathrm{kg} / \mathrm{m}^{2}\right)$ & $24.2 \pm 3.89$ & $22.5 \pm 3.12$ \\
Enrolment body weight $(\mathrm{kg})$ & $69.4 \pm 11.82$ & $66.7 \pm 9.12$ \\
Body weight when delivering (kg) & $73.5 \pm 11.93$ & $71.0 \pm 9.43$ \\
Average weekly body weight change (kg/w) & $0.3 \pm 0.20$ & $0.3 \pm 0.15$ \\
Gestational body mass change $(\mathrm{kg})$ & $11.6 \pm 3.27$ & $10.5 \pm 4.07$ \\
Post-enrolment body weight change $(\mathrm{kg})$ & $4.3 \pm 2.59$ & $4.1 \pm 1.93$ \\
\hline
\end{tabular}

The patients' age, pre-gestational BMI, enrolment body weight, pre-delivery body weight, gestational body weight increase and average weekly body weight increase showed no statistical difference $(\mathrm{P}>0.05)$.

\subsection{Result of Laboratory Examinations}

Laboratory investigations were carried out to evaluate effects of preload treatment (intervention group) compared to controls at the time of enrolment and at the time of delivery. Hemoglobin, glycosylated hemoglobin, total protein, albumin, liver function, renal function, blood lipids showed no statistical difference $(\mathrm{P}>0.05)$, as shown in Table 2. The laboratory examination results at enrolment showed no statistical difference between the two groups after grouping by age and $\mathrm{BMI}(\mathrm{P}>0.05)$. Routine laboratory examinations carried out at the time for delivery did not reveal any differences (Table 2).

As shown in Table 3, preload treatment (intervention group) lead to a statistical difference $(\mathrm{P}<0.05)$ when preload treatment was compared to control treatment in $\geq 5 \%$ HbA1C change and glucose control stabilization time (week). Upon grouping by age, no difference of glycemic control stabilization time and $\geq 5 \%$ glycosylated hemoglobin change was observed in patients $<30$ years (Table 4). The stabilization time for glycemic control was faster in preload treated patients $\geq 30$ years old compared to the control group. In patients $\geq 30$ years of age the number of subjects who had a change (increase) of $\geq 5 \%$ of HbA1c was lower in the preload treated group than in the control group $(\mathrm{P}<0.05)$ (Table 4). Regarding BMI and stabilization time for blood glucose, both subgroups of pregestational $B M I<24 \mathrm{~kg} / \mathrm{m}^{2}$ and $B M I \geq 24 \mathrm{~kg} / \mathrm{m}^{2}$ showed a shorter time in the intervention group than in the control group $(\mathrm{P}<0.05)$ (Table 5). In patients with BMI $\geq 24 \mathrm{~kg} / \mathrm{m}^{2}$, the number of subjects who had a change (increase) of $\geq 5 \%$ of $\mathrm{HbA1c}$ was lower in the preload treated group than in the control group, which was statistically significant $(\mathrm{P}<0.05)$.

Table 2. Laboratory examination

\begin{tabular}{|c|c|c|c|c|}
\hline & \multicolumn{2}{|c|}{ At Enrolment } & \multicolumn{2}{|c|}{ At Delivery } \\
\hline & $\begin{array}{c}\text { Control group } \\
(\mathrm{n}=15)\end{array}$ & $\begin{array}{l}\text { Intervention group } \\
\quad(\mathrm{n}=25)\end{array}$ & $\begin{array}{c}\text { Control group } \\
(\mathrm{n}=15)\end{array}$ & $\begin{array}{l}\text { Intervention group } \\
(\mathrm{n}=25)\end{array}$ \\
\hline $\mathrm{Hb}(\mathrm{g} / \mathrm{L})$ & $117.7 \pm 8.58$ & $118.8 \pm 9.05$ & $121.0 \pm 9.72$ & $126.5 \pm 9.02$ \\
\hline HbA1c (\%) & $5.3 \pm 0.31$ & $5.4 \pm 0.31$ & $5.5 \pm 0.30$ & $5.5 \pm 0.29$ \\
\hline TP $(\mathrm{g} / \mathrm{L})$ & $64.9 \pm 4.97$ & $65.7 \pm 3.44$ & $63.0 \pm 5.85$ & $64.3 \pm 3.92$ \\
\hline ALB (g/L) & $37.0 \pm 2.81$ & $39.8 \pm 5.86$ & $35.3 \pm 2.97$ & $37.4 \pm 6.33$ \\
\hline ALT(U/L) & $14.7 \pm 7.67$ & $13.0 \pm 6.07$ & $14.0 \pm 6.39$ & $11.8 \pm 5.88$ \\
\hline AST(U/L) & $18.6 \pm 9.96$ & $16.3 \pm 5.42$ & $20.3 \pm 8.42$ & $17.5 \pm 4.26$ \\
\hline $\mathrm{Cr}(\mu \mathrm{mol} / \mathrm{L})$ & $44.1 \pm 5.12$ & $47.2 \pm 6.48$ & $45.7 \pm 8.31$ & $50.0 \pm 8.65$ \\
\hline BUN (mmol/L) & $2.9 \pm 0.68$ & $3.0 \pm 0.67$ & $3.1 \pm 0.66$ & $3.3 \pm 0.94$ \\
\hline $\mathrm{TC}(\mathrm{mmol} / \mathrm{L})$ & $5.7 \pm 1.06$ & $6.0 \pm 1.12$ & $5.9 \pm 1.29$ & $6.6 \pm 1.05$ \\
\hline $\mathrm{TG}(\mathrm{mmol} / \mathrm{L})$ & $2.7 \pm 1.03$ & $2.5 \pm 1.10$ & $3.6 \pm 1.31$ & $3.6 \pm 1.66$ \\
\hline
\end{tabular}

Blood samples were prepared for analysis at our clinical chemistry department. Parameters measured were; haemoglobin (Hb), glycated haemoglobin (HbA1c), total protein (TP),Albumin (Alb), alanine aminotransferase (ALT), aspartate aminotransferase (AST), creatinine (Cr),blood urea nitrogen (BUN), total cholesterol (TC), triglycerides (TG). Routine laboratory examinations carried out at enrollment and at the time for delivery did not reveal any differences $(\mathrm{P}>0.05)$.

Table 3. Pregnancy Outcome and Blood Glucose Control

\begin{tabular}{lcc}
\hline & $\begin{array}{c}\text { Control group } \\
(\mathrm{n}=15)\end{array}$ & $\begin{array}{c}\text { Intervention group } \\
(\mathrm{n}=25)\end{array}$ \\
\hline Natural l abour & $7(46.7 \%)$ & $14(56 \%)$ \\
Postpartum haemorrhage & $3(20 \%)$ & $3(12 \%)$ \\
Premature rupture of foetal membranes & $2(13.3 \%)$ & $5(20 \%)$ \\
Foetal macrosomia & $3(20 \%)$ & $3(12 \%)$ \\
Premature delivery & $1(6.7 \%)$ & $1(4.0 \%)$ \\
Birth weight (g) & $3527 \pm 504$ & $3320 \pm 470$ \\
Height (cm) & $50 \pm 1.9$ & $50 \pm 2.1$ \\
$\geq 5 \%$ HbA1C change* & $8(53.3 \%)$ & $4(16 \%)$ \\
Glucose control stabilization time (week)* & $2.3 \pm 1.1$ & $1.2 \pm 0.5$ \\
\hline
\end{tabular}

Data was collected from the control group and the intervention, preload treated group. The Table indicates mean \pm standard deviation or number of patients (percentage) within each category in each group. * means $\mathrm{P}<0.05$, indicating statistical difference between the two groups within age category. 
Table 4. Pregnancy Outcome and Blood Glucose Control in Different Age Groups

\begin{tabular}{|c|c|c|c|c|}
\hline & \multicolumn{2}{|c|}{ Age $<30$ years } & \multicolumn{2}{|c|}{ Age $\geq 30$ years } \\
\hline & $\begin{array}{c}\text { Control group } \\
(n=3)\end{array}$ & $\begin{array}{l}\text { Intervention group } \\
(\mathrm{n}=5)\end{array}$ & $\begin{array}{c}\text { Control group } \\
(\mathrm{n}=12)\end{array}$ & $\begin{array}{l}\text { Intervention group } \\
(\mathrm{n}=20)\end{array}$ \\
\hline Natural labour & $3(100 \%)$ & $5(100 \%)$ & $4(33.3 \%)$ & $9(45.0 \%)$ \\
\hline Postpartum haemorrhage & $1(33.3 \%)$ & $1(20 \%)$ & $2(16.7 \%)$ & $2(10.0 \%)$ \\
\hline Premature rupture of foetal membranes & $0(0 \%)$ & $2(40 \%)$ & $2(16.7 \%)$ & $3(15.0 \%)$ \\
\hline Foetal macrosomia & 0 & 0 & $3(25.0 \%)$ & $3(15.0 \%)$ \\
\hline Premature delivery & 0 & 0 & $1(8.3 \%)$ & $1(5.0 \%)$ \\
\hline Birth weight (g) & $3683 \pm 445$ & $3542 \pm 225$ & $3487 \pm 528$ & $3265 \pm 503$ \\
\hline Height (cm) & $51 \pm 1.7$ & $50 \pm 1.7$ & $50 \pm 2.0$ & $50 \pm 2.1$ \\
\hline$\geq 5 \%$ HbA $1 \mathrm{C}$ change & $2(66.7 \%)$ & $2(40 \%)$ & $6(50 \%)$ & $2(10 \%)^{*}$ \\
\hline Glucose control stabilization time (week) & $1.3 \pm 0.6$ & $1.2 \pm 0.5$ & $2.5 \pm 1.1$ & $1.3 \pm 0.6^{*}$ \\
\hline
\end{tabular}

Patients were divided into age groups $<30$ years and $\geq 30$ years of age. * means $\mathrm{P}<0.05$, indicating statistical difference between the two groups within age category.

Table 5. Pregnancy Outcome and Blood Glucose Control in Different BMI

\begin{tabular}{|c|c|c|c|c|}
\hline & \multicolumn{2}{|c|}{$\begin{array}{l}\text { Pre-gestational } \\
\mathrm{BMI}<24 \mathrm{~kg} / \mathrm{m}^{2}\end{array}$} & \multicolumn{2}{|c|}{$\begin{array}{l}\text { Pre-gestational } \\
\mathrm{BMI} \geq 24 \mathrm{~kg} / \mathrm{m}^{2}\end{array}$} \\
\hline & $\begin{array}{l}\text { Control group } \\
(n=7)\end{array}$ & $\begin{array}{l}\text { Intervention group } \\
\qquad(\mathrm{n}=16)\end{array}$ & $\begin{array}{l}\text { Control group } \\
(n=8)\end{array}$ & $\begin{array}{l}\text { Intervention group } \\
\qquad(\mathrm{n}=9)\end{array}$ \\
\hline Postpartum haemorrhage & $1(14.3 \%)$ & $2(12.5 \%)$ & $2(25.0 \%)$ & $1(11.1 \%)$ \\
\hline Premature rupture of foetal membranes & $1(14.3 \%)$ & $4(25.0 \%)$ & $1(12.5 \%)$ & $1(11.1 \%)$ \\
\hline Foetal macrosomia & 0 & $2(12.5 \%)$ & $3(37.5 \%)$ & $1(11.1 \%)$ \\
\hline Birth weight (g) & $3237 \pm 386$ & $3431 \pm 415$ & $3780 \pm 472$ & $3124 \pm 523 *$ \\
\hline Height (cm) & $49 \pm 1.5$ & $50 \pm 2.1$ & $51 \pm 1.3$ & $49 \pm 1.9 *$ \\
\hline$\geq 5 \%$ HbA1C change & $2(28.6 \%)$ & $3(18.8 \%)$ & $6(75.0 \%)$ & $1(11.1 \%)^{*}$ \\
\hline Glucose control stabilization time (week) & $1.9 \pm 0.7$ & $1.3 \pm 0.6^{*}$ & $2.6 \pm 1.3$ & $1.2 \pm 0.4^{*}$ \\
\hline
\end{tabular}

Patients were put in groups according to pre-gestational BMI.

$* \mathrm{P}<0.05$, indicating significant differences between intervention and control group.

\subsection{Pregnancy Outcome}

Several parameters were used to document pregnancy outcome. In the pregestational $\mathrm{BMI} \geq 24 \mathrm{~kg} / \mathrm{m}^{2}$ subgroup, there was no statistical difference in the incidence of fetal macrosomia, but both the new-born birth weight and height were lower than that of the control group, which was statistically significant $(\mathrm{P}<0.05)$.

\section{Discussion}

Our study shows that macronutrient preload is safe and can be used to treat hyperglycemia in patients with gestational diabetes mellitus, GDM. We demonstrate that blood glucose is stabilized to a euglycemic level faster in the preload treated group compared to the control group. The time to stabilize blood sugar was reduced to around half of the time in controls and this seemed to be the case especially in women $\geq 30$ years and in those with a pre-gestational body mass index $\geq 24 \mathrm{~kg} / \mathrm{m}^{2}$. The favorable impact on blood glucose was also reflected by HbA1c, which was better controlled in the preload treated group. We also showed that birth weight was significantly reduced in the older and overweight participants on preload treatment, most likely an effect of the improved blood sugar control in the intervention group.

In hyperglycemic pregnant women the use of insulin therapy is only considered for those patients in whom blood glucose control is inadequate after 1-2 weeks of diet regimens. Data on diet interventions as the sole GDM treatment are however limited and its actual role in maternal and newborn outcomes has scarcely been studied [13]. Moreover, in clinical practice, most of the dietary recommendations for patients with GDM are based mainly on glucose control, through glucose monitoring data, instead of being based on data from clinically more relevant endpoints, especially for the patient, such as need for insulin for the mother and new born outcomes. In a recent systematic metanalyses of dietary interventions it was concluded that low Glycemic Index, GI, was the only feature of the diet that significantly correlated to hard outcomes like new-born birth weight and less need for insulin treatment [13]. Preload, also called pre-meal, is a new medical nutrition therapy that has gained increased clinical acceptance during the last 5 years $[11,12,14]$. In contrast to diet, with a content that vary from time to time, preload is based on a specific blend of ingredients, and may thus be tested in RTCs. The majority of preload studies are based on protein preload, of which whey and pea protein seems to be most effective $[15,16]$, although other macronutrients also contribute to the preload effect. Ideally a preload should include only a small amount of calories and have a low GI. The NGC preload contains a high degree of macronutrients (three different proteins, complex carbohydrates, dietary fiber, Omega 3/6 fatty acids), has a low GI and delivers only $71 \mathrm{kcal}$ per portion.

In clinical investigations, this macronutrient preload method effectively helps to control the blood glucose of patients with type 2 diabetes [17,18] and preload treatment also can reduce body weight gain in type 2 diabetic subjects. The mode of preload action is a relevant point of 
discussion. It is our working hypothesis, supported by data, that the macronutrient preload activates the so called incretin response leading to the release of gastrointestinal peptides including GLP-1 (Glucagon-like Peptide 1), which in turn will slow gastric emptying, modulate insulin secretion and stimulate the satiety earlier $[9,17]$. With reference to the latter most of our patients given NGC Preload report that they had a reduced sense of hunger before dining and could easier control the size of meal portions.

One of our parameters, "Glucose control stabilization time" is of particular interest since it truly reflects the situation in clinical practice. After detection of hyperglycaemia during gestational week 24-28, the routine is nutrition education and diet control as the cornerstone of reducing the elevated blood sugar. Unfortunately this often fail, according to a recent Cochrane review on diet advice and GDM [7] no significant dietary benefit was shown in any of the selected studies. The consequence is to put the woman on insulin, or in some countries oral antidiabetic drugs. Our parameter, time to normalize the blood glucose, is relevant since it early signals if the intervention is effective, and may continue until delivery.

There is a great need to find safe and effective procedures to treat gestational diabetes and this is the case not only from the maternal point of view but also from the short and long term perspective of the offspring. Uncontrolled hyperglycemia during pregnancy increases the incidence of fetal macrosomia [19,20,21], which in turn increases the risk of offspring's obesity, the impact of which could continue until adulthood [22,23]. Bodyweight is a controllable factor and active gestational body mass control is important for prevention of fetal macrosomia. As the patients with pre-gestational $\mathrm{BMI} \geq 24 \mathrm{~kg} / \mathrm{m}^{2}$ more easily will increase weight above recommended limits during pregnancy [24], weight control for such patients is important, and may further reduce the risk of fetal macrosomia. This may be the reason for the better pregnancy outcome in the intervention group than control group. However, with the limitation of the small number of patients in our study, there was no statistical difference between the two groups. In addition to increased risks for birth complications recent data also have demonstrated increased risks for children born by mothers with gestational diabetes to develop obesity/diabetes and also neurodevelopmental disorders (ADHD) [25].

More research is needed to further substantiate the findings in the present investigation. It would be of interest to investigate a larger number of patients and also patients of different ethnicities. The possibility that age/BMI is a factor that regulates preload responses should also be investigated.

\section{Conclusion}

This pilot study shows that macronutrient preload is a promising new medical nutrition therapy for blood glucose control in gestational diabetes mellitus. Preload normalizes hyperglycemia within a short time, and may

thus reduce the need for insulin or antidiabetic drugs during pregnancy. In this small group of patients preload also appears to provide a better control of glycosylated hemoglobin. By affecting the weight of the new born, as shown in the participants with pregestational $\mathrm{BMI} \geq 24 \mathrm{~kg} / \mathrm{m}^{2}$, preload treatment is likely to facilitate a smooth delivery, although further studies are needed to confirm this. Preload intervention represents a valuable addition to conventional treatment of gestational diabetes mellitus, and may in the near future be used as first line treatment after discovery of hyperglycemia during pregnancy.

\section{References}

[1] Bellamy L, Casas J-P, Hingorani AD, Williams D. Type 2 diabetes mellitus after gestational diabetes: a systematic review and metaanalysis. Lancet 2009 May 23; 373(9677): 1773-9.

[2] Damm P, Houshmand-Oeregaard A, Kelstrup L, Lauenborg J, Mathiesen ER, Clausen TD. Gestational diabetes mellitus and long-term consequences for mother and offspring.Diabetologia (2016) 59: 1396-1399.

[3] Kennelly MA, McAuliffe FM. Prediction and prevention of Gestational Diabetes: an update of recent literature. Eur J Obstet Gynecol Reprod Biol. 2016 Jul; 202: 92-8.

[4] Camprubi Robles M, Campoy C, Garcia Fernandez L, LopezPedrosa JM, Rueda R, Martin MJ. Maternal Diabetes and Cognitive Performance in the Offspring: A Systematic Review and Meta-Analysis. PLoS One. 2015 Nov 13; 10 (11).

[5] Djelmis J, Pavić M, Mulliqi Kotori V, et al. Prevalence of gestational diabetes mellitus according to IADPSG and NICE criteria. Int J Gynecol Obstet (2016).

[6] Wei YM, Yang HX. Comparison of the diagnostic criteria for gestational diabetes mellitus in China. Zhonghua fu chan ke za zhi 2011; 46: 578-81 (in Chinese).

[7] International Association of Diabetes and Pregnancy Study Groups Consensus Panel, Metzger BE, Gabbe SG, Persson B, Buchanan TA, et al. International association of diabetes and pregnancy study groups recommendations on the diagnosis and classification of hyperglycaemia in pregnancy. Diabetes Care, 2010, 33(3): 676-682.

[8] Han S, Crowther CA, Middleton P, Heatley E. Different types of dietary advice for women with gestational diabetes mellitus. Cochrane Database Syst Rev 2013; 3:CD00927.

[9] Ma J, Stevens JE, Cukier K et al. Effects of a protein preload on gastric emptying, glycemia, and gut hormones after a carbohydrate meal in diet-controlled type 2 diabetes. Diabetes Care. 2009, 32(9): 1600-1602.

[10] Shah M, Vella A. Effects of GLP-1 on appetite and weight. Rev Endocr Metab Disord. 2014 Sep; 15(3): 181-7.

[11] Ma J, Jesudason DR, Stevens JE et al. Sustained effects of a protein 'preload' on glycaemia and gastric emptying over 4 weeks in patients with type 2 diabetes: A randomized clinical trial. Diabetes Res Clin Pract. 2015 May; 108 (2).

[12] Li CJ, Norstedt G, Hu ZG, et al. Effects of a Macro-Nutrient Preload on Type 2 Diabetic Patients. Front Endocrinol. 2015 Sep 16; 6: 139.

[13] Viana LV, Gross JL, Azevedo MJ. Dietary Intervention in Patients with Gestational Diabetes Mellitus: A Systematic Review and Meta-analysis of Randomized Clinical Trials on Maternal and Newborn Outcome. Diabetes Care 2014; 37: 3345-3355.

[14] Li L, Xu J, Zhu W, et al. Effect of a macronutrient preload on blood glucose level and pregnancy outcome in gestational diabetes. Journal of Clinical \& Translational Endocrinology 5 (2016) 36-4.

[15] Silva Ton WT, das Graças de Almeida C , Marvila Girondoli Y, et al. Effect of different protein types on second meal postprandial glycaemia in normal weight and normoglycemic subjects. Nutr Hosp. 2014 Mar1; 29(3): 553-8.

[16] Abou-Samra R, Keersmaekers L, Brienza D, Mukherjee R, Macé K. Effect of different protein sources on satiation and short-term satiety when consumed as a starter. Nutr J. 2011 Dec 23; 10: 139.

[17] Akhavan T, Luhovyy BL, Panahi S, Kubant R, Brown PH, Anderson GH. Mechanism of action of pre-meal consumption of whey protein on glycaemic control in young adults. The Journal of Nutritional Biochemistry, 2014, 25(1): 36-43. 
[18] Xiaoqing F, Chen H, Jie Z, et. al. Effect of Preload with Whey Protein on Postprandial Blood Glucose in Patients with Type 2 Diabetes. Food and Nutrition in China. 2014, 20(11): 78-80.

[19] Guanghui, Zhaoming, Li, Weiyuan. 2011 Current Status and Risk Factor Investigation on Foetal Macrosomia in China. 10th Chinese Medical Association Gynaecology and Obstetrics Academic Conference, 2012.

[20] Hildén K, Hanson U, Persson M, Fadl H. Overweight and obesity: a remaining problem in women treated for severe gestational diabetes. Diabet Med. 2016 Aug; 33(8): 1045-51.

[21] Li Y, Chen X, Chen S. Effect of Pre-gestational body mass and Gestational Weight Gain on Newborn Birth Outcome and Pregnant Women Perinatal Outcome. Chinese Journal of Epidemiology. 2014, 35(6): 635-640.
[22] Mamun AA, O'Callaghan M, Callaway L, Williams G, Najman J, Lawlor DA. Associations of gestational weight gain with offspring body mass index and blood pressure at 21 years of age: evidence from a birth cohort study. Circulation, 2009, 119(13): 1720-1727.

[23] Ludwig DS, Currie J. The association between pregnancy weight gain and birth weight: a within-family comparison. Lancet, 2010, 376(9745): 984-990.

[24] Godoy AC, Nascimento SL, Surita FG. A systematic review and meta-analysis of gestational weight gain recommendations and related outcomes in Brazil. Clinics (Sao Paulo). 2015, 70(11): 758-764.

[25] Perna R, Loughan AR, Le J, Tyson K. Gestational Diabetes: Long-Term Central Nervous System Developmental and Cognitive Sequelae. Appl Neuropsychol Child. 2015; 4(3): 217-220. 